\title{
Correction to: A C*-algebraic Approach to Interacting Quantum Field Theories
}

\author{
Detlev Buchholz $^{1}$ (1), Klaus Fredenhagen ${ }^{2}$ \\ 1 Mathematisches Institut, Universität Göttingen, Bunsenstr. 3-5, 37073 Göttingen, Germany \\ E-mail: buchholz@theorie.physik.uni-goettingen.de \\ 2 II. Institut für Theoretische Physik, Universität Hamburg, Luruper Chaussee 149, 22761 Hamburg, Germany
}

Published online: 18 September 2021 - ㄷ The Authors 2021

\section{Correction to: Commun. Math. Phys. https://doi.org/10.1007/s00220-020-03700-9}

The article A $\mathrm{C}^{*}$-algebraic Approach to Interacting Quantum Field Theories written by Detlev Buchholz and Klaus Fredenhagen was originally published electronically on the publisher's internet portal on [07 March 2020] without open access. With the author(s)' decision to opt for Open Choice the copyright of the article changed on [11 May 2021] to CThe Author(s) 2020 and the article is forthwith distributed under a Creative Commons Attribution Open Access funding enabled and organized by Projekt DEAL.

Open Access This article is distributed under the terms of the Creative Commons Attribution 4.0 International License (http://creativecommons.org/licenses/by/4.0/), which permits unrestricted use, distribution, and reproduction in any medium, provided you give appropriate credit to the original author(s) and the source, provide a link to the Creative Commons license, and indicate if changes were made.

Publisher's Note Springer Nature remains neutral with regard to jurisdictional claims in published maps and institutional affiliations. 